\title{
Research on the Motivation of Core Staff in Small and Medium - sized High - tech Enterprises
}

\author{
Yingchao Bai \\ College of Business Administration, Heyuan Polytechnic, Heyuan, Guangdong, 517000, China \\ baiying168@163.com
}

Keywords: High-Tech Companies, Core Staff, Motivation.

\begin{abstract}
First, we introduced the theoretical basis of core employee motivation research. Second, we put forward the concept and characteristics of high-tech enterprises and core employees, and pointed out that the motivation measures of core employees should take the characteristics of core employees as the starting point. Third, based on the analysis of the current situation of high tech enterprise core employees, we clarified the main problems of core employee motivation. Finally, we put forward the countermeasures to inspire the core staff from four aspects: salary motivation, achievement motivation, work environment motivation and development opportunity motivation
\end{abstract}

\section{Introduction}

Since 1960s, the theory of enterprise has been rising, and the theory of motivation has been produced [1]. The incentive problem has always been the core issue of management. Management scientists may be able to accurately predict, plan and control financial and material resources [8]. However, it is difficult to predict and control the human resources, especially the inner potential and effort. Thus, motivation becomes a key function of management. In the process of high-tech enterprises in China, the role of knowledge workers, especially the core staff, is more and more important [4].

As an important type of human capital, core employees play a key role in the organization. It is the core competitive resources of enterprises, and it has an important impact on the performance of enterprises. Therefore, a reasonable incentive mode can not only mobilize the enthusiasm of the core staff, but also has a positive significance for the long-term development of enterprises.

(1) It provides the basis for the core staff to participate in the distribution of human capital.

The value created by knowledge-based human capital owners is far greater than its wage value [3]. If they cannot participate in the distribution of value, it will dampen their enthusiasm, thus hindering the realization of business goals. Based on the contribution of various factors in the industry, the enterprise distributes the benefits. Therefore, for knowledge-based human capital, the enterprise profit distribution is based on the importance of the value of knowledge employees [2].

(2) Analyze the core employee's demand characteristics to achieve effective incentives.

At present, many enterprises still despise the core staff, which will inevitably lead to enterprises in a very dangerous situation [5]. At the same time, enterprise knowledge-based human capital is different from the general staff. Their greatest feature is the extraordinary ability to profit outside the organization. In accordance with the distribution principle of more pay for more work, their pay and benefits should be proportional to their value. Reasonable value determination can provide scientific basis for core staff salaries and bonuses, and can fully mobilize the enthusiasm, initiative and creativity of human capital owners [6]. This is conducive to the core staff to play a greater efficiency, and improve the economic benefits of the organization.

(3) It provides management human capital information for enterprises.

Through value assessment, it can provide management information to the management of human capital. Based on this, we can determine whether employees meet the needs of enterprises. In addition, it can also provide complete decision information. With the transformation of economic growth model, human capital plays an increasingly important role. For the evaluation of the development 
potential and profitability of enterprises, we are no longer only based on the measurement of material capital. Human capital determines the development of the enterprise.

\section{State of the art}

Among the foreign scholars' research on the incentive of core staff, the most representative is the theory of human capital mixed employment model of the University of Maryland and the Cornell University professor (1999) [7]. From the point of view of enterprise strategy development, they synthesize the theory of transaction cost economics, human capital theory and strategic management theory, and put forward the theory of human capital mixed employment model for strategic construction of human capital. The theory holds that human capital is a key resource for enterprises to produce competitive advantage, but not all employees are equally important to the enterprise. The human capital in the organization can be divided into four types according to the dual dimension of "the value of human capital" and "the scarcity of human capital". Enterprises can adopt different employment patterns for four different types of human capital, establish different employment relationships, and manage them differently. Among them, the first type of human capital has high value and high uniqueness. That is to say, these employees have the skills that are specific to the enterprise, which are difficult to obtain in the labor market, and the strategic benefits that employees bring to enterprises are far more than the cost of hiring and developing their management. For the high value and high scarcity of human capital, the enterprise regards it as the core staff that has the competitive advantage, and carries on the internal development from the strategy.

Domestic scholar Liu Zhiqiang (2001) put forward the theory of human resources management [9]. That is, according to individual ability, personal contribution, personal career interests, personal development potential, the importance of personal positions and personal social background, the organization of all employees are roughly divided into A, B, C three categories. Among them, Class A employees are the core employees of the enterprise. Generally, there are special contributors, occupying important posts, good social relations, great development prospects, rich professional knowledge and extraordinary technical expertise. For such employees, the organization must arrange key positions according to their individual competencies, technical expertise and individual wishes, and implement key management. For those who have occupied key positions, enterprises should implement key monitoring and regular inspection. Core employees hold more private information. There are hidden behavior and hidden information of moral hazard. Therefore, the organization of its effective incentive and supervision is to let the core staff to become the company's shareholders.

Based on game theory and goal setting theory, Zhejiang University's Kong Zhiqiang and Xing Yiqun (2003) proposed a specific incentive model for core employees [10]. From the perspective of the incentive subject and the incentive object, the two sides carry on the game based on the information owned by the core staff and the enterprise, and finally reach the balance and realize it in the form of contract.

In general, scholars at home and abroad in theory and practice made a different degree of discussion and research in the core staff of the incentive. However, the vast majority of these studies focus on one aspect of the core staff. For the senior leadership of the enterprise, the core staff incentive is a systematic problem. Therefore, it is necessary for us to continue to strengthen the research in this field.

\section{Analysis on the characteristics of core employees in high - tech enterprises}

Many scholars have studied the characteristics of core employees. Compared with the general staff, the core staff has the following characteristics.

\subsection{High work and academic ability}

Core employees usually have a high level of skills and expertise, and they also have the ability to learn and innovate continuously. The core employees facing the environment is usually changeable, and the uncertain working mode and content cannot be a simple copy. There are not too many can refer to things, all this determines the core staff must have higher work ability and learning ability. 
Learning is also a feature of the core staff. Knowledge updates more quickly, and the staff working environment is constantly changing. The dynamic development of retaining ability is a prerequisite to maintain their own core competitiveness of core employees, only continuous learning can make the core staff to maintain good professional skills. In addition, the core staff have a higher pursuit of knowledge and career, which also makes them have a higher willingness to learn.

\subsection{Undertake an important position in the enterprise}

Although some of the staff for the enterprise is the core staff, such as the middle and senior managers. However, different positions for different enterprises, the value is very different. Therefore, the judgment of different enterprises for important positions is not the same. For example, for companies like Microsoft, software engineers are no doubt important post, excellent program developers are Microsoft's core staff. American Express Company believes that the driver of the enterprise is the core staff. The reason is that the driver is the hub of the company's business operations, and the driver has the necessary skills in the courier business. They understand the characteristics of the route, and they also dominate the relationship with the customer.

\subsection{Strong personal influence}

Influence is the ability of a person to change the mind and behavior of others in association with others. The value of the core staff for the enterprise is not limited to his own direct contribution to the enterprise, but also reflected in his influence on other employees. Although the individual's psychological cognition has the subjective nature of consciousness, the psychological cognition of others and the spiritual environment of the organization are still an objective restriction factor. There is a two-way process between employees, and employees and organizations. Employees change their ideas, values, and adjust their behavior through the awareness and understanding of other people's psychological behavior and organizational environment. It can be seen that the core staff have a strong impact on the surrounding staff.

\subsection{High work autonomy}

Core employees in the enterprise has a strong independence and autonomy. Core employees usually have a high level of cultural quality and knowledge. They have a strong ability to access and apply knowledge and information. Therefore, the core staff usually want to have greater freedom and decision in the work. This independence is manifested in the consciousness and initiative of work attitude. In the way of work, they do not want to be more control and constraints. At the same time, they also attach importance to the necessary support from the enterprise. In the working environment, they require a more flexible workplace, working hours and relaxed organizational atmosphere, that is, they tend to a more autonomous working environment, emphasizing self-management and selfrestraint. In the work of the content, the core staff performance is often difficult to track in real time, and their work process is usually difficult to control. Sometimes, it is difficult to accurately quantify the results of the work, which brings some difficulty to performance evaluation.

\subsection{High self-fulfilling demand}

Self-fulfilling demand refers to the need for a person to fulfill his or her own potential and achieve an ideal. Compared with ordinary employees, the core staff often have a more persistent pursuit of the cause. They are more likely to pursue a sense of satisfaction and achievement from the job itself, and are highly expected to be respected and recognized by the community. They will not be content to passively complete the general business. They are constantly to achieve self-transcendence, and regard a challenging goal as a way of self-actualization.

\section{Incentive countermeasures for core employees of high - tech enterprises in China}

\section{1 incentive measures based on compensation}

Compared to other incentives, salary incentive is the core staff of the basic living security. It is more able to reflect the timeliness and authenticity of incentives. The establishment of a complete and reasonable pay system is the prerequisite for maximizing pay. Reasonable remuneration is one of the key factors in retaining core employees. From the function, the salary can be divided into two parts. The first part is the return of employee labor value. This part is mainly to protect the basic material life of employees and their families, which plays a health role. The other part is the incentive 
to reward the staff. The so-called incentive compensation system refers to the introduction of incentive factors in the pay system design. The establishment of the pay system will not only enable employees to get a reasonable return, but also to stimulate the role of staff. Although the high salary of the enterprise can retain the core staff, it will lead to the increase in the cost of business. Low pay makes the employee's labor consumption not properly compensated, which will affect the core staff of the labor initiative and work mood, resulting in the core staff flow to a higher salary of the enterprise. The establishment of incentive compensation system is to stimulate the enthusiasm of the core staff through the incentive factors in the compensation system, so as to achieve the purpose of retaining core employees. Two problems should be paid attention to in establishing incentive compensation system: The first is the design of the protection part. The basic part of the guarantee is mainly to protect the basic material needs of employees and their families. However, it cannot significantly lower the basic salary of competitors than others, otherwise, it can protect the basic needs of employees, but could not retain the core staff. The second is the design of the incentive part. The incentive part of the incentive design must be guided, and it has a substantial incentive-oriented utility. The compensation system of core employees can be divided into the following categories:

(1) Annual salary system

This salary system applies to the senior management of the enterprise. It is paid a fixed salary in years for the unit. Fixed salary can provide a more stable environment and security, which is conducive to their work. In the western developed countries, the annual salary system is very popular. In recent years, it was introduced to China, and the effect is very good in many large and mediumsized enterprises after the implementation.

(2) Project contract revenue system

This kind of system is different from our country's individual contract system in the early stage of reform and opening up. On the basis of concluding a contract with the contractor, the contractor shall give the contractor the right to operate the enterprise within a certain period of time, and the contractor shall guarantee to pay the profits as stipulated in the contract. This system has basically been abolished because of the short-term effects. The project contract revenue system is aimed at the technical development personnel and part of the project manager, and the project that they contracted is only part of the business. In practice, many companies have canceled basic monthly salary or retained a small portion of this core employee, and linked their earnings to the technical development projects that they are responsible for. In this way, the market efficiency is good, the employee's income is high. Thus, it mobilizes the enthusiasm of the core employees of technology. Project contract income is generally higher than the original fixed income, otherwise, no one is willing to take such a big risk and pressure.

(3) Bonus system

The bonus system is widely used in Chinese enterprises. Wages and bonuses generally constitute the main cash income of employees. Through the issuance of monthly bonuses and annual bonuses, companies can determine the results of performance appraisal and timely feedback to the staff, which can provide a good competitive atmosphere for the staff. However, in practice, in order to obtain bonuses, the core staff tend to pay more attention to short-term effects and ignore the long-term development of enterprises. In accordance with performance standards, the enterprise pay too much bonus to the core staff, which will not only cause the general staff of dissatisfaction, but also swallowed the company's valuable cash flow. Therefore, from the domestic and international development trend, the bonus has been gradually replaced by long-term incentives.

(4) Commission system

In general, the commission system is mainly used for sales of core employees. The commission is generally equaled to the product of sales or sales rate and commission rate. It can be based on sales volume, or based on the growth rate or the number of new customers within a certain period of time. If the enterprise takes into account the impact of objective economic factors, the commission system can be designed as part of the commission of employee income. The other part is in the form of a basic salary, and it may also be based on the portion of the sales amount that is deducted from the quota. 


\section{(5) Welfare plan}

The welfare plan of the enterprise mainly includes the way of living welfare, security welfare and education welfare. Among them, the living welfare and security benefits are to meet the basic needs of employees and safety protection, and it is generally not related to the level and position of employees. Its specific forms include transport subsidies, health benefits and other living benefits. Compared with the former, the benefits of education and training are more incentive, which is more obvious for senior managers. Education and training benefits include job training, corporate fees, newspaper subscriptions and so on. On the one hand, it satisfies the needs of top management who are eager to further improve. On the other hand, it improves the ability of employees, which in turn will have a positive impact on the production and management efficiency of the enterprise.

\subsection{Motivations based on work achievement}

Core employee achievement incentives include job challenges, job importance, work value, skill diversity, job content enrichment, and task integrity. Core employees like to engage in challenging work, and their innovative ability is also higher than the general type of staff. Therefore, enterprises must stimulate their creativity, give full play to their creativity, and make this ability to achieve business goals. First, companies allow them to work on their favorite jobs, encourage them to build self-managed teams, give them full autonomy, and support their innovative activities as much as possible from human, material, financial, and time. Second, companies should be tolerant of the various attempts at their core employees, and should not elaborate on the content and methods of their work, as long as their work contributes to the improvement of business efficiency. Third, companies should put the core staff of the innovative activities into the enterprise development plan, so that they understand what companies need most. Thus, enterprises guide them to work closely with the development strategy of the enterprise. Finally, for the core staff, long-term unilateral work will make them feel tired of the work. Therefore, job enrichment can mobilize the enthusiasm of the core staff.

When the core staff successfully completed the work, they will get a sense of achievement, and this sense of accomplishment comes from the work itself. Compared to other work, these jobs require strong skills. According to Maslow's hierarchy theory, this demand is self-fulfilling. Therefore, compared to other incentives, the achievement of inspiration can make the core staff to obtain a corresponding sense of accomplishment from the work, and the employees can be self-motivated. Only this incentive mechanism can make the core staff feel their creativity has been fully played. To get the better place in the competition of human resources, the companies must pay more attention to the retention management of core employees.

\subsection{Motivations based on development opportunities}

The core staff self-development goal is not only to meet the existing work, but also to lay the foundation for future career development. They are eager to self-growth, self-development, and selfrealization. They join the enterprise not only to get material rewards, but also hope to play their own expertise. If an enterprise cannot be developed, they are likely to leave the company to seek new development opportunities. Therefore, enterprises not only provide core staff with a commendable commune, but also improve the personnel training mechanism and establish career development plan. Enterprises should provide them with the opportunity to receive education and improve their skills, so that they have the ability to work for a lifetime.

Through the career development plan, both enterprises and employees can profit by the following ways: from the performance of core employees, companies can profit. In a challenging career, employees can earn money. In the career development planning, the enterprise should guide the core staff to connect personal development with the development of the organization. When an employee enters a business, there is a clear career development plan that provides a variety of alternative development opportunities for the employee. In addition to the promotion of the administrative level, employees can also be developed from the technical level, work redesign and other aspects, so that employees have a practical grasp of the future.

The era of knowledge economy is an era of rapid development of science and technology and knowledge explosion. New technology and new information emerge one after another, while the old information and the old technology are eliminated at the same speed. At this point, learning is no 
longer a stage of life, no knowledge can be useful for life. Only by constantly learning and enterprising, employees can keep up with the pace of the times, and will not be eliminated by the times. Although the core staff has a high culture and skill, if they are not timely supplement of new knowledge and technology to master, one day they will run out of ideas. Therefore, enterprises should pay attention to the training of core employees, and to provide them with a variety of learning and training opportunities, so they can clearly see their prospects in the development of enterprises, and achieve self-satisfaction.

For the core staff, on the one hand, enterprises should be fully authorized according to business requirements, allowing employees to develop their own good work methods. On the other hand, it is necessary to provide the financial, material and human support for the creative work independently undertaken by the core staff, so as to ensure the smooth progress of its innovative activities. Facts have proved that the core staff to participate in decision-making can fully feel the trust and respect of the enterprise. Core employees have the expertise and skills, so they are most aware of the problem situation, the way of improvement and the customer's real thoughts. When employees have a stronger sense of participation in corporate affairs and more autonomy, their sense of responsibility for work will be greatly increased.

\section{Conclusion}

From the perspective of enterprise human resource management, through the analysis of the characteristics of core employees and the current situation of the core employees of high-tech enterprises, we put forward the incentive measures for the core staff from three aspects, which is the reward incentive, achievement incentive and development incentive. For enterprise managers and human resources workers, these management strategies have some help and reference.

Due to the limited level and resources, this paper also has many shortcomings. In the incentive measures, this paper gives only a train of thought. In order to better solve the problem of high-tech enterprise core staff incentive, we should accumulate practical experience in the future work, and put forward more comprehensive and operable core staff incentive measures.

\section{Acknowledgments}

Fund Project: The 12th Five-Year Plan Subject of Social Science Association of Heyuan City: human resources security research of small and medium-sized enterprises in Heyuan City (project number: HYSK14P11)

Scientific and Technological Projects of Heyuan Polytechnic, Investigation and Research on the Influencing Factors of Human resource security in Private Enterprises in Heyuan City (Project No. 2014KJ07).

\section{References}

[1] Anitha, J., and Farida N. Begum. "Role of Organisational Culture and Employee Commitment in Employee Retention." ASBM Journal of Management 9.1 (2016): 17.

[2] Boyd, Neil, et al. "Sense of Community, Sense of Community Responsibility, and Public Service Motivation as Predictors of Employee Well-Being and Engagement in Public Service Organizations." The American Review of Public Administration (2017): 0275074017692875.

[3] Frazier, M. Lance, and Christina Tupper. "Supervisor Prosocial Motivation, Employee Thriving, and Helping Behavior: A Trickle-Down Model of Psychological Safety." Group \& Organization Management (2016): 1059601116653911.

[4] Kontoghiorghes, Constantine. "Linking high performance organizational culture and talent management: satisfaction/motivation and organizational commitment as mediators." The International Journal of Human Resource Management 27.16 (2016): 1833-1853. 
[5] Porter, Tracy H., Kelly Diane Riesenmy, and Dail Fields. "Work environment and employee motivation to lead: Moderating effects of personal characteristics." American Journal of Business 31.2 (2016): 66-84.

[6] Rasheed, Muhammad Imran, et al. "Factors affecting teachers' motivation: An HRM challenge for public sector higher educational institutions of Pakistan (HEIs)." International Journal of Educational Management 30.1 (2016): 101-114.

[7] Strauss, Karoline, Sharon K. Parker, and Deirdre O'Shea. "When does proactivity have a cost? Motivation at work moderates the effects of proactive work behavior on employee job strain." Journal of Vocational Behavior 100 (2017): 15-26.

[8] Sobral, Filipa, Maria José Chambel, and Filipa Castanheira. "Managing motivation in the contact center: The employment relationship of outsourcing and temporary agency workers." Economic and Industrial Democracy (2016): 0143831X16648386.

[9] Take, Naoki, et al. "The effect of 5S-Continuous Quality Improvement-Total Quality Management approach on staff motivation, patients' waiting time and patient satisfaction with services at hospitals in Uganda." Journal of Public Health in Africa 6.1 (2016): 45.

[10] Zhang, Jian, et al. "The different relations of extrinsic, introjected, identified regulation and intrinsic motivation on employees' performance: Empirical studies following self-determination theory." Management Decision 54.10 (2016): 2393-2412. 